\title{
MUTU KADAR AIR DALAM BAHAN BAKAR GAS DI SEKTOR TRANSPORTASI DARAT DAN TEKNIK MITIGASINYA
}

\author{
Quality of Water Levels in Gas Fuel in The Land Transportation Sector And Its \\ Mitigation Engineering
}

\author{
Lisna Rosmayati \\ Pusat Penelitian dan Pengembangan Teknologi Minyak dan Gas Bumi "LEMIGAS" \\ JI. Ciledug Raya Kav. 109, Cipulir, Kebayoran Lama, Jakarta Selatan, DKI Jakarta, Indonesia. \\ Email:lisna.rosmayati@esdm.go.id / lisna5968@gmail.com
}

\begin{abstract}
Abstrak
Penggantian bahan bakar yang ramah lingkungan di sektor transportasi darat, salah satunya adalah bahan bakar gas (BBG) atau compressed natural gas. Bahan bakar gas dipilih karena cadangannya yang masih cukup banyak tetapi belum maksimal pemanfaatannya. Emisi yang dihasilkan BBG pun juga sangat kecil. Penurunan konsumsi bahan bakar gas di sektor transportasi menunjukkan adanya kendala dan permasalahan yang tidak kunjung terselesaikan. Untuk saat ini, kendaraan yang masih menggunakan bahan bakar gas adalah bajaj, bus TransJakarta dan sedikit kendaraan dinas pemerintah. Jumlah Stasiun Pengisian Bahan Bakar Gas (SPBG) di beberapa wilayah di Indonesia juga terus berkurang karena menurunnya jumlah kendaraan yang menggunakan bahan bakar gas. Spesifikasi BBG harus memenuhi persyaratan standar yang dapat memberikan rasa aman dalam pengoperasian kendaraan bermotor dan peralatan terkait lainnya. Kontrol kualitas bahan bakar tersebut menjadi sangat penting, terutama dalam hal mengontrol kandungan uap air dalam bahan bakar gas tersebut. Tujuan makalah ini adalah untuk memberikan informasi teknis dan gambaran umum pentingnya batasan mutu kadar air dalam bahan bakar gas yang digunakan pada kendaraan bermotor di sektor transportasi darat. Metode pengukuran kadar air dilakukan secara onsite analysis dengan menggunakan ASTM D-1141. Hasil pengukuran di beberapa SPBG di Indonesia menunjukkan kadar air yang cukup tinggi. Pengendalian dan pengukuransenyawa kontaminan dalam Bahan Bakar Gassangatlah penting karena kontaminan yang melebihi batas spesifikasi menjadi potensi bahaya untuk pengguna kendaraan bermotor. Dengan monitoring dan penetapan spesifikasi batasan kontaminan dalam BBG yang tepat, maka kadar air dalam bahan bakar gas bisa dikendalikan.
\end{abstract}

Kata Kunci : BBG, kadar air, mutu

\begin{abstract}
Diversification of energy which friendly fuels in the transportation sector, one of which is gas fuel (BBG) or compressed natural gas. Gas fuel was chosen because there are still quite a lot of reserves but the maximum utilization is not yet. BBG emissions are also very small. The decline in gas fuel consumption in the transportation sector shows that there are obstacles and problems that cannot be resolved. Vehicles that still use natural gas are bajaj, TransJakarta buses and a few government service vehicles. The number of Gas Refueling Stations (SPBG) in several regions in Indonesia also continues to decrease due to the decreasing number of vehicles that use gas fuel. CNG specifications must meet standard requirements that can provide a sense of security in the operation of motor vehicles and other related equipment. Quality control of these fuels becomes very important, especially in terms of controlling the content of water vapour in the fuel gas. The purpose of this paper is to provide technical information and a general description of the importance of limiting the quality of water content in gas fuels use in motor vehicles in the land transportation sector. The method of measuring water content is carried out onsite analysis using ASTM D-1142. The measurement results in several SPBG in Indonesia show that the water content is quite high, The control and measurement of comtaminant compounds in gas fuel is very important because contaminants that exceed the specification limits become a potential hazard for motor vehicle users. By monitoring and determining the exact limit of contaminant specifications in the CNG, the water content in natural gas can be controlled.
\end{abstract}

Keywords: BBG, water content, quality

\section{PENDAHULUAN}

Pertumbuhan jumlah kendaraan bermotor terus meningkat setiap tahunnya seiring dengan jumlah pertambahan penduduk, walaupun pemerintah telah banyak menyediakan fasilitas kendaraan publik yang aman dan nyaman. Walau demikian, masih banyak masyarakat yang masih menggunakan kendaraan pribadi dalam beraktivitas apapun. Peningkatan kendaraan bermotor tentunya 
akan meningkatkan kebutuhan akan bahan bakar kendaraan atau energi. Pemerintah saat ini sedang berupaya untuk meminimalkan penggunaan energi berbahan bakar minyak dan terus mengembangkan penggunaan bahan bakar gas khususnya di sektor transportasi darat. Berdasarkan hasil penelitian J.Norris (2002), dengan menggunakan BBG (BBG) dapat mengurangi emisi $\mathrm{CO}_{2}$ sebesar 30\%.

Sebagian besar pengguna bahan bakar gas di kota-kota besar seperti Jakarta dan Surabaya keluhannya terkait dengan kualitas dari bahan bakar gas tersebut. Kandungan kontaminan uap air dan senyawa sulfur atau merkuri dalam bahan bakar masih menjadi topik pembahasan. Dengan adanya senyawa asam, kandungan kadar air dalam konsentrasi berapapun akan berdampak bahaya dan merusak mesin serta peralatan BBG lainnya. Pengukuran kadar air dalam BBG dilakukan dengan metode ASTM D-1142 dan kontrol kualitas dilakukan secara random di beberapa Stasiun Pengisian Bahan Bakar Gas (SPBG). Hasil pengukuran menunjukkan bahwa sebagian besar kadar air dalam BBG di beberapa Stasiun Pengisian Bahan Bakar Gas melebihi batasan yang dipersyaratkan oleh Direktorat Jenderal Migas (Ditjen Migas) selaku Regulator Minyak dan Gas Bumi dilndonesia.

BBG adalah Bahan Bakar Gas. Komposisi utamanya gas metana dan disertai gas lainnya yang prosentasinya berbeda antara satu sumber dengan sumber lainnya (Rahardjo Tirtoatmodjo, 1999). Saat ini kendaraan-kendaraan publik di kota-kota besar telah menggunakan bahan bakar gas (BBG) karena dinilai lebih bersih dan pemanfaatan bahan bakar gas di dalam negeri masih belum maksimal. Komposisibahan bakargas (BBG)untuk sektor transportasi, spesifikasinya harus memenuhi persyaratan standar yang memberikan rasa aman dalam pengoperasian kendaraan bermotor dan peralatan terkait yang diperlukan untuk pengisian, pemanfaatan dan pemeliharaannya. Kandungan air dalam produk BBG seringkali menjadi permasalahan utama dan menjadi penyebab berbagai kerusakan dan kecelakaan terkait dengan pemanfaatan gas bumi di sektor transportasi. Komposisi BBG sebagai bahan bakar kendaraan bermotor akan menentukan besaran nilai kalor BBG, densitas dan wobbe indexnya (ISO 6976 Natural Gas: 1995). Selain itu produk BBG yang berkualitas dan bersih mampu melindungi instalasi sistem bahan bakar gas dari kerusakan yang diakibatkan oleh korosi dan pengendapan material.Di Indonesia penetapan parameter spesifikasi dan batasan-batasan BBG umumnya merupakan hasil konsensus bersama dari para pemangku kepentingan. Batasan kadar air dalam bahan bakar gas bumi di Indonesia seringkali tidak dapat dipenuhi karena keterbatasan fasilitas yang dimiliki di SPBG. Permasalahan yang dihadapi di lapangan cukup berat bagi perusahaan penyuplai BBG untuk dapat mencapai kandungan air dengan nilai $3 \mathrm{lb} / \mathrm{mmscf}$, sehingga harus ada evaluasi apakah konsentrasi kadar air yang ditetapkan tersebut sudah tepat atau masih dapat ditoleransi sampai konsentrasi tertentu tanpa berdampak kepada mesin dan peralatan BBG lainnya. Penyediaan fasilitas pengering untuk mengeringkan gas bumi seringkali menjadi keluhan produsen gas bumi karena tingginya biaya pengadaan pengering dan nilai penjualan gas bumi yang tidak sebanding (Lisna, 2014)

Tujuan dari tulisan ilmiah ini adalah untuk memberikan informasi teknis dan gambaran umum pentingnya batasan mutu kadar air dalam bahan bakar gas (BBG) yang digunakan pada kendaraan bermotor di sektor transportasi darat, menjelaskan hasil pengukuran dan batasan maksimal kadar air dalam BBG dan menjelaskan kelebihan Bahan bakar gas (BBG) sebagai bahan bakar alternatif untuk kendaraan bermotor yang murah dan ramah lingkungan.

Makalah ini membahas parameter kontaminan kadar air dalam bahan bakar gas (BBG) dan teknik pengukurannya. keuntungan penggunaan bahan bakar gas dibanding dengan bahan bakar minyak dari segi ekonomi dan lingkungan.

\section{TINJAUAN PUSTAKA}

\section{a. Bahan Bakar Gas (BBG)}

Di Indonesia, kita mengenal CNG sebagai bahan bakar gas (BBG). Gas alam terkompresi atau BBG, adalah gas alam di bawah tekanan yang tetap jernih, tidak berbau, dan non-korosif. Meskipun kendaraan dapat menggunakan gas alam baik sebagai cairan atau gas, kendaraan yang paling menggunakan bentuk gas dikompresi untuk tekanan di atas $3.100 \mathrm{lbm}$ per inci persegi. BBG adalah alternatif bahan bakar selain bensin atau solar. Bahan bakar ini dianggap lebih 'bersih' bila dibandingkan dengan dua bahan bakar minyak karena emisi gas buangnya yang 
ramah lingkungan. BBG dibuat dengan melakukan kompresi metana $(\mathrm{CH} 4)$ yang diekstrak dari gas alam. BBG disimpan dan didistribusikan dalam bejana tekan, biasanya berbentuk silinder. Konversi ke CNG difasilitasi dengan pemberian harga yang lebih murah bila dibandingkan dengan bahan bakar cair (bensin dan solar), peralatan konversi yang dibuat lokal dan infrastruktur distribusi BBG yang terus berkembang. Sejalan dengan semakin meningkatnya harga minyak dan kesadaran lingkungan, BBG saat ini mulai digunakan juga untuk kendaraan penumpang dan truk barang berdaya ringan hingga menengah. Sesungguhnya di Indonesia, BBG bukanlah barang baru. Pencanangan untuk menggunakan BBG yang harganya lebih murah dan lebih bersih lingkungan daripada bahan bakar minyak (BBM) sudah dilakukan sejak tahun 1986(Risdyanta,2008).

Spesifikasi Bahan Bakar Gas (BBG) terdiri dari Metana : 95\% - 97\% ; Nilai Kalor Kotor (Gross Heating Value) : 8,000-10,658 $\mathrm{Kcal} / \mathrm{M}^{3}$ (900-1200 BTU/SCF) ; SG : 0.55 0.85 ; Water Content:0.16028 gr/M ${ }^{3}$ (10 Lbs/MMSCF)(LIPI,2011). Dilndonesia, penggunaan bahan bakar BBG untuk kendaraan bermotor sudah dilaksanakan sejak tahun 1995 dan BBG ini terus mengalami perubahan trend seiring dengan pola konsumsi masyarakat di Indonesia. Compressed Natural Gas (BBG) merupakan bahan bakar gas yang dibuat dengan melakukan kompresi metana $\left(\mathrm{CH}_{4}\right)$. BBG disimpan dan didistribusikan dalam bejana tekan berbentuk silinder. BBG memiliki tekanan 200 bar dengan tangki yang lebih besar daripada LGV (NFPA 52: 2006). BBG digunakan di daerah-daerah yang memiliki sumber gas atau terdapat sistem pipa gas bumi. Dengan alasan ini pulalah SPBG BBG terbatas jumlahnya dan hanya terdapat di daerah-daerah tertentu. Hingga saat ini, identifikasi kendaraan yang menggunakan BBG adalah wilayah-wilayah seputar Jabodetabek dan Surabaya, dan hanya angkutan umum (angkot, taxi dan busway) yang jumlahnya teridentifikasi, sedangkan jumlah kendaraan pribadi dan kendaraan dinas belum ada data yang representative (Aziz ML, Paramita W, 2011)

Standar dan mutu BBG untuk kendaraan bermotor masih banyak ditemui kendala baik teknis maupun non-teknis (apa saja) di lapangan sehingga standar dan mutu (spesifikasi) tersebut harus dikaji ulang dan dievaluasi sehingga parameter dan batasan nilai yang ditetapkan sesuai dengan kondisi dan iklim di Indonesia dan dapat diterima serta disepakati oleh semua pihak tanpa mengurangi kepentingan keselamatan berkendara. Kajian teknis karakteristik penggunaan bahan bakar BBG pada kendaraan bermotor juga menjelaskan pengaruh komposisi BBG yang berdampak pada kualitas BBG sebagai bahan bakar gas untuk kendaraan bermotor terkait dengan batasan masingmasing komposisi BBG tersebut dalam spesifikasi. Gas bumi dengan kandungan uap air yang tinggi dapat membentuk hidrat padat atau semi padatan yang menyerupai es pada temperatur operasi yang rendah dan tekanan yang tinggi. Hidrat merupakan hasil dari kristalisasi senyawa air dengan senyawa metana dan atau etana pada kondisi tertentu, yang dapat menyumbat dan menyebabkan masalah pada instalasi sistem pemakaian bahan bakar gas. Air merupakan pemicu terbentuknya senyawasenyawa korosif melalui penggabungan dengan komponen lain dalam gas bumi, seperti karbondioksida dan hidrogen sulfida. Kadar air dalam BBG perlu dibatasi (Tulus B. Sitorus, MT, 2002).

\section{b. Pegaruh Iklim terhadap Batasan Kandungan Air dalam BBG}

Dua parameter BBG yang sangat dipengaruhi oleh temperature ambien adalah water content (kadar air) dan kondensasi hidrokarbon. Sama halnya dengan zat lain, perubahan fasa dari gas menjadi cair atau yang dikenal sebagai kondensasi dipengaruhi oleh temperatur dan tekanan. Temperatur BBG pada container maupun sistem pengisian BBG sangat dipengaruhi oleh temperature ambien karena dinding containernya/sistem pengisian yang berhubungan langsung dengan udara ambient. Tekanan kerja pada container BBG kurang lebih sekitar 200-250 bar (Bukacek, R.F.,1955)

Temperatur pada saat uap air dalam gas bumi mulai terkondensasi disebut water dew point, sedangkan temperatur pada saat hidrokarbon terkondensasi disebut hydrocarbondew point. Kandungan air di dalam gas bumi harus dijaga pada suatu level tertentu agar menjamin pada saat suhu terendah dan tekanan maksimal, uap air tidak mengalami kondensasi (Robinson, J.N., Wiekert E., Moore R.G., 1978) Kondensasi uap air menjadi air akan menimbulkan korosi pada alat-alat 
berbahan metal termasuk container. Untuk mencegah terjadinya kondensasi uap air, SAE J1616 menyarankan agar temperature dew point harus dijaga agar maksimal berada $10^{\circ} \mathrm{F}$ atau $5.6^{\circ} \mathrm{C}$ di bawah temperatur terendah yang terjadi di suatu wilayah tempat beroperasinya kendaraan BBG. Gambar dibawah adalah chart yang menghubungkan korelasi antara kadar air dalam lb/MMscf ( sumbu y), temperatur dew point dalam ${ }^{\circ} \mathrm{F}$ ( sumbu $\mathrm{x}$ ), dan tekanan dalam psig (garis yang membelah chart).

Untuk komposisi hidrokarbon BBG, Hydrocarbon dew point ditentukan oleh komposisi hidrokarbon dalam BBG.
Kondensasi hidrokarbon terutama terjadi di kontainer pada saat tekanan turun. Kondensasi hidrokarbon harus dihindari karena dapat menyebabkan terganggunya kinerja/performance kendaraan. Pengukuran kadar air (dew point wáter) pada bahan bakar gas dilakukan dengan metode stándar ASTM D-1142.

Dalam prakteknya konsentrasi kadar air dalam BBG dalam suatu sistem penyimpanan (storage) seperti di kendaraan berbahan bakar gas dibatasi untuk mencegah agar uap air di dalam gas bumi tersebut tidak berada dalam keadaan saturasi dan akhirnya terkondensasi.

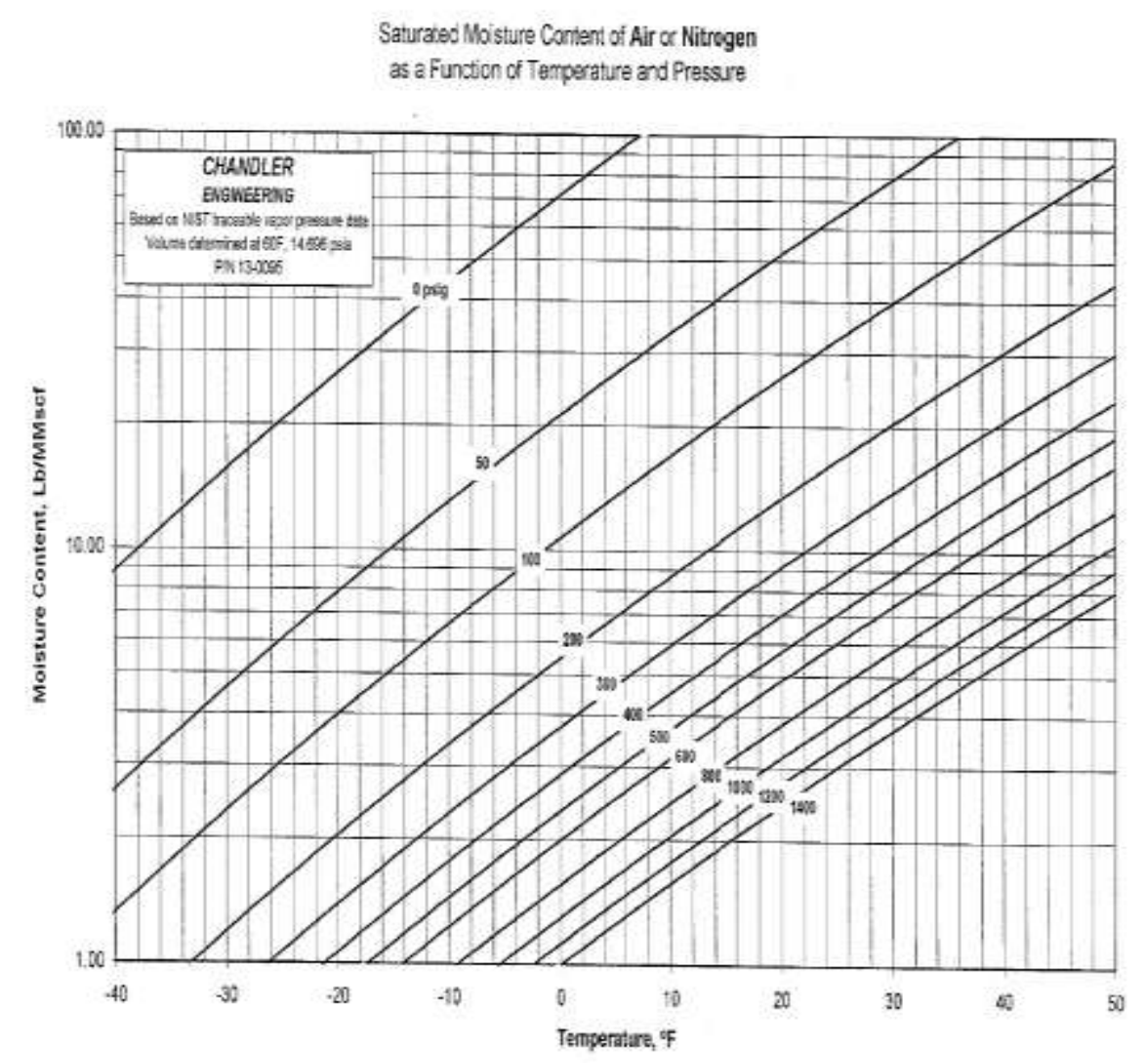

Gambar 1. Chart Moisture content in Natural Gas 


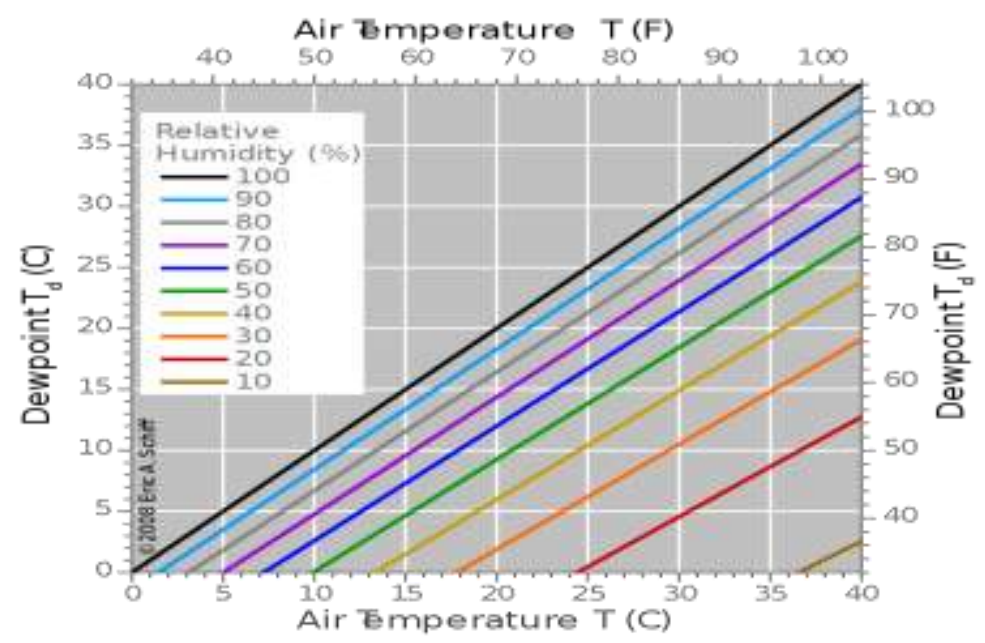

Gambar 2. Grafik Relative Humidity (\%) terhadap Dew Point Temperatur

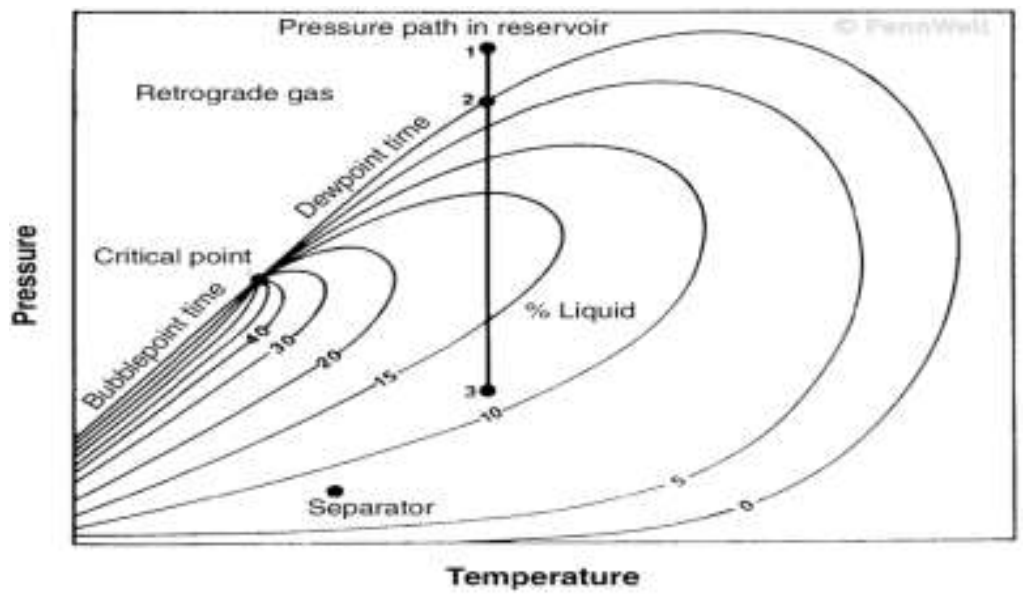

Gambar 3. Phase diagram of a retrograde-condensate gas (William D. McCain, 1990)

Kadar air umumnya dinyatakan dalam berbagai cara:

- Massa air per volume gas, lb/MMscf

- Dew point temperature, ${ }^{\circ} \mathrm{F} /{ }^{\circ} \mathrm{C}$ bila tekanan diketahui

Pembatasan kadar air di dalam gas bumi bergantung kepada keadaan iklim setempat dengan tujuan agar air dalam fasa gas tidak terkondensasi menjadi fasa cair. Kadar air dalam gas bumi pada saat saturasi tergantung temperatur dan tekanan (Oellrich, L.R., Althaus, K, 2002). Dengan bertambahnya tekanan gas, maka kadar air menurun, dan dengan bertambahnya temperatur maka kadar air bertambah (R. E. Kirk and D. F. Othmer, 1995). Persamaan di bawah ini menyatakan hubungan antara kadar air di gas bumi pada saat saturasi dengan tekanan dan temperaturnya.
$\underset{0.81462}{W_{w a t e r}}=593335 \cdot \exp \left(0.05486 \cdot t_{G}\right) \cdot P_{G}^{-}$

Dimana $w_{\text {water }}$ dalam kilogram air per $10^{6}$ $\mathrm{m}^{3}$ gas bumi, $T_{G}$ temperature gas bumi dalam celcius, dan $P_{G}$ pressure gas bumi dalam MPa (ISO 15403: 2000)

\section{c. Verifikasi dan kalibrasi Dew Point Tester}

Verifikasi sebuah metode bertujuan untuk membuktikan bahwa laboratorium yang bersangkutan mampu melakukan pengujian dengan metode tersebut dengan hasil yang valid. Disamping itu verifikasi juga bertujuan untuk membuktikan bahwa laboratorium memiliki data kinerja. Definisi verifikasi dalam standar ISO/IEC 17025:2005 sama dengan definisi verifikasi dalam ISO 9000:2005 pada poin 3.8.4(ISO 9000:2008). Verifikasi merupakan salah 
satu cara pengujian hipotesis yang tujuan utamanya adalah untuk menemukan kesesuaian.

Verifikasi pengujian kadar air dilakukan untuk menjamin bahwa peralatan dalam hal ini adalah dew point tester telah diverifikasi dan siap untuk digunakan. Verifikasi bisa juga dilakukan dengan menggunakan bahan CRM (Certified Material Standard).

\section{METODE PENELITIAN}

Tahapan pelaksanaan kegiatan pengendalian mutu kandungan air dalam BBG dilakukan dengan menggunakan metode ASTM D-1142 yaitu Standard Test Method for Water Vapor Content of Gaseous Fuels by Measurement of Dew-Point Temperatur. Tahapan pelaksanaan sebagai berikut

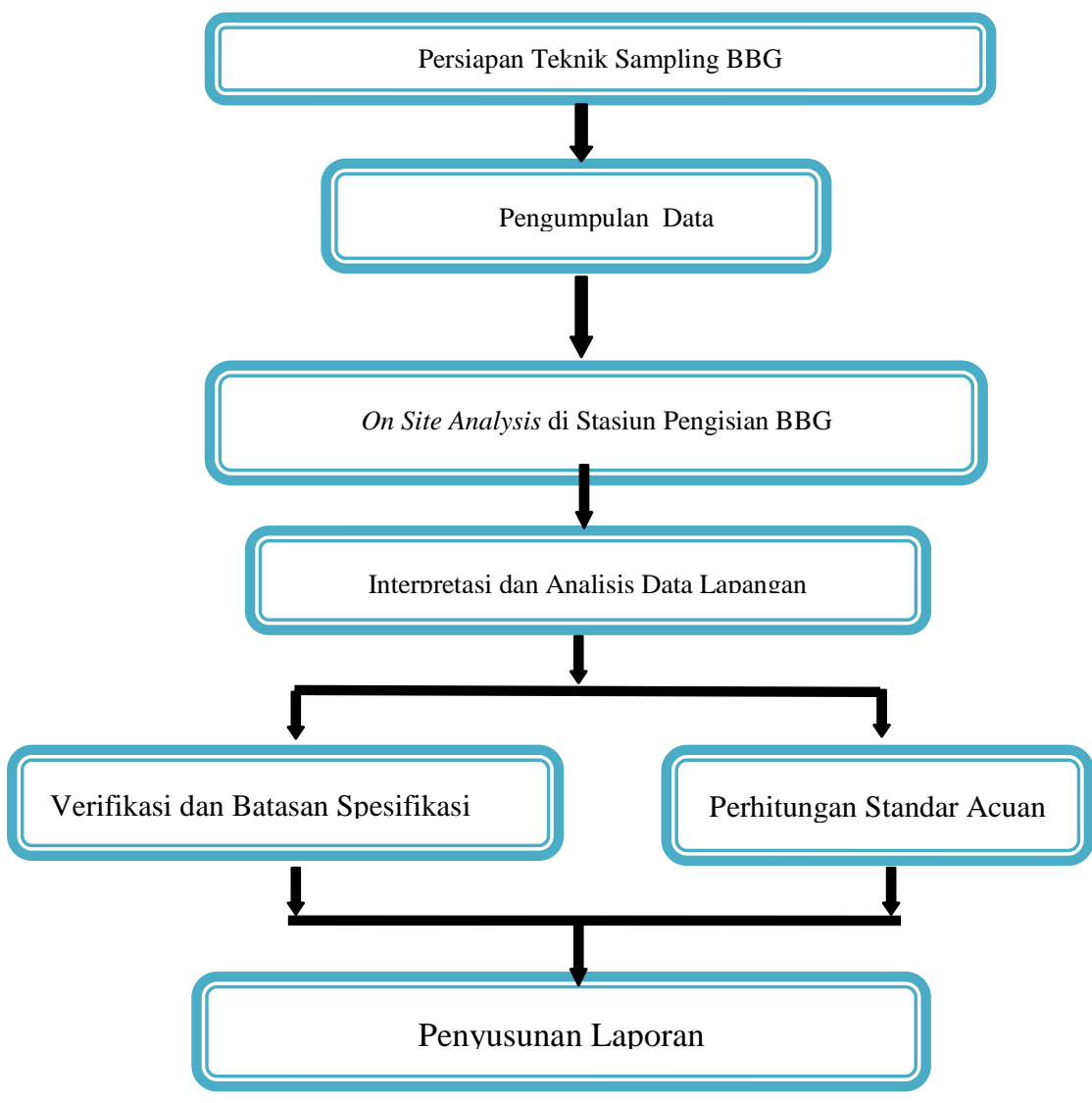

Gambar 4. Tahapan kegiatan

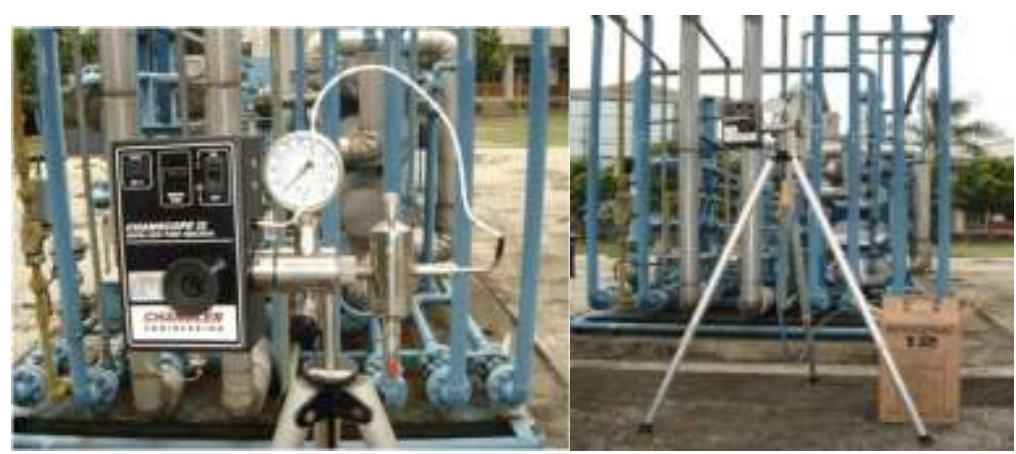

Gambar 5. Pengukuran water content di lapangan gas dengan Chandler 


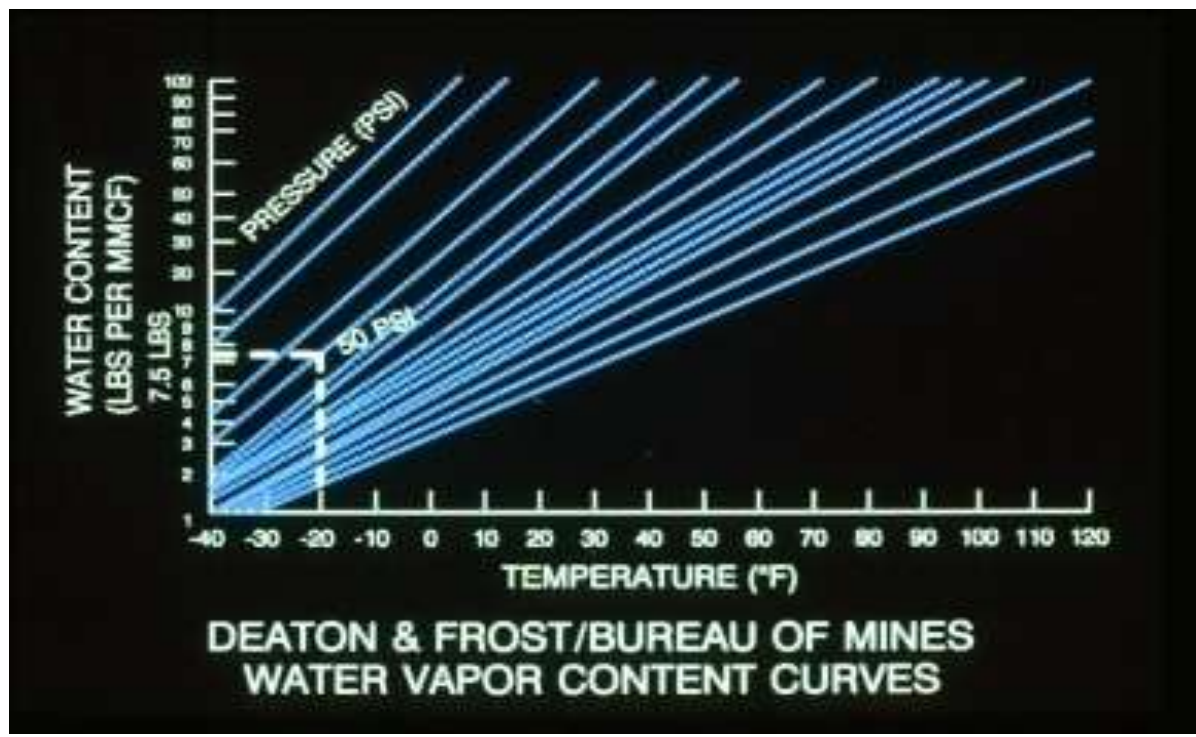

Gambar 6. Hubungan water content (Ibs/MMSCF) terhadap temperature

- Catat temperatur Dew Point dan Tekanan gas sumber.

- Tentukan kandungan air dengan hitungan dari ASTM D-1142 atau dengan bantuan karta / diagram yang sudah ada.

- Melakukan beberapa analisis secara onsite di beberapa SPBG untuk mengukur langsung kadar air dan partikulatnya. Dari hasil pengukuran kadar air di beberapa wilayah dan didasarkan pada kondisi iklim atau temperature terendah di Indonesia, maka akan dengan mudah diprediksi proses kondensasi di dalam tabung pada tekanan operasi tabung, sehingga proses kondensasi tersebut bisa dihindari.

\section{HASIL DAN PEMBAHASAN}

Hasil pengukuran kadar air dalam BBG di bberapa SPBG di Jabodetabek yang telah dilakukan oleh tim kami dapat dilihat pada Tabel 1.Data kadar air (Lb/MMSCFD) merupakan rata-rata dari hasil pengukuran yang dilakukan minimal 5 kali pengukuran. Sebagian besar SPBG tersebut telah dilengkapi sistim drier gas untuk menurunkan kadar air dalam bahan bakar gas dan scrubber untuk menurunkan jumlah partikulatnya. Tabel 1 menunjukkan hasil pengukuran kadar air dalam bahan bakar gas BBG di beberapa SPBG di Indonesia pada tahun 2018.

Tabel 1. Kadar air dalam BBG di beberapa SPBG

\begin{tabular}{clc}
\hline NO & LOKASI & $\begin{array}{c}\text { KADAR AIR } \\
\text { ((Lb/MMSCFD) }\end{array}$ \\
\hline 1 & $\begin{array}{l}\text { SPBG } \\
\text { Kalimantan }\end{array}$ & 4,87 \\
\hline 2 & $\begin{array}{l}\text { SPBG Jakarta } \\
\text { Barat }\end{array}$ & 19,70 \\
\hline 3 & $\begin{array}{l}\text { SPBG Jakarta } \\
\text { Timur }\end{array}$ & 4,53 \\
\hline 4 & SPBG Bogor & 5,78 \\
\hline 5 & $\begin{array}{l}\text { SPBG Jakarta } \\
\text { Timur }\end{array}$ & 7,78 \\
\hline 6 & $\begin{array}{l}\text { SPBG Jawa } \\
\text { Timur J J J }\end{array}$ & 35,60 \\
\hline 7 & $\begin{array}{l}\text { SPBG Sumatera } \\
\text { Selatan }\end{array}$ & 14,90 \\
\hline
\end{tabular}

Kualitas BBG yang digunakan pada kendaraan transportasi di Indonesia, masih memiliki kadar air yang cukup tinggi. Tampaknya memang kandungan uap air dalam BBG merupakan masalah yang penting untuk diselesaikan bersama. Jika kita melihat SK Dirjen Migas tahun 2011 tentang spesifikasi BBG, kadar uap air dibatasi maksimum 3,0 $\mathrm{lb} / \mathrm{mmscf}$. Batasan tersebut merupakan hasil konsensus pada tahun 2010 dengan catatan kadar air dalam gas dari hulu dimonitor. Maksud dari pernyataan tersebut adalah bahwa kandungan uap air dalam bahan bakar BBG tidak boleh melebihi batasan 3,0 lb/mmscf. Hal tersebut sulit untuk dipenuhi oleh sebagian besar SPBG karena faktor kapasitas drier gas yang dimiliki dan kandungan uap air dalam BBG dari produsen yang memang masih tinggi, kisarannya berkisar $10-20 \mathrm{lb} / \mathrm{mmscf}$. Sementara 
berdasarkan informasi dari Stasiun Pengisian BBG (SPBG), aktual kadar uap air masih sekitar 7,0 10,0 (atau bahkan lebih) $\mathrm{lb} / \mathrm{mmscf}$. Penggunaan drier memang dapat mengurangi kadar air, namun jika kadar air BBG dari kilangnya atau produsen BBG memang cukup tinggi, setelah melewati drier pun kadar uap airnya masih di atas spesifikasi SK Dirjen Migas. Dari kasus tersebut memang diperlukan spesifikasi gas yang cukup kering dari supplier gas (Pertagas dan PGN) sebelum masuk ke sistem pengisian BBG.

Tabel 2 di bawah ini merupakan usulan hasil konsensus yang menjelaskan batasan minimum dan maksimum masing-masing komponen dalam bahan bakar gas dan parameter lain yang terkait dengan kualitas bahan bakar gas (BBG). Setiap komponen dan parameter uji memiliki satuan dan metode uji yang harus di informasikan.

Analisis permasalahan dibahas dengan mengacu pada standar internasional dan parameter komposisi yang ada dalam standar spesifikasi BBG, berasal dari dua lembaga internasional, SAE J1616 dan ISO 15403. Secara umum standar SAE J1616 dan ISO 15403 memiliki kesamaan jenis parameter yang dicakup, kedua standar tersebut samasama menjelaskan parameter kadar air dalam bahan bakar BBG (SAE J1616: 1994-02) dan (ISO 15403:2000)

Komponen BBG yang banyak menimbulkan permasalahan di lapangan adalah kandungan uap airnya. Hal ini karena uap air dalam BBG dapat terkondensasi pada tekanan dan temperatur tertentu dan bereaksi dengan komponen karbondioksida atau senyawa sulfur menghasilkan senyawa asam yang bersifat sangat korosif (EPA-650/2-75030). Hal inilah yang seringkali menjadi permasalahan karena dapat merusak tabung BBG, peralatan dan fasilitas BBG. Kualitas bahan bakar gas yang digunakan pada kendaraan transportasi di Indonesia, masih memiliki kadar air yang cukup tinggi. Tampaknya memang kandungan uap air dalam BBG merupakan masalah yang penting untuk diselesaikan bersama. Jika kita melihat SK Dirjen Migas tahun 2011 tentang spesifikasi BBG, kadar uap air dibatasi maksimum $3,0 \quad \mathrm{lb} / \mathrm{mmscf}$. Sementara berdasarkan informasi dari Stasiun Pengisian BBG (SPBG), aktual kadar uap air masih sekitar 7,0 10,0 (atau bahkan lebih) $\mathrm{lb} / \mathrm{mmscf}$. Persyaratan keamanan BBG yang penting sebagai bahan bakar kendaraan bermotor harus mempunyai temperatur titik embun air yang sangat rendah, untuk mencegah terbentuknya air pada berbagai kondisi tekanan dan temperatur. Gabungan senyawa korosif dan fluktuasi tekanan yang disebabkan oleh konsumsi bahan bakar serta pengisian kembali bahan bakar ke dalam tabung BBG dapat menyebabkan keretakan yang berkelanjutan terhadap material logam dan akhirnya menimbulkan kerusakan. Tekanan pada saat temperatur titik embun air dari bahan bakar sebaiknya disesuaikan dengan lokasi geografis dimana kendaraan bermotortersebut beroperasi dan harus diatur, sehingga kondensasi air tidak terjadi di dalam tabung BBG pada saat tekanan operasi maksimum.

Tabel 2. Hasil Kesepakatan Konsensus BBG 2014

\begin{tabular}{lcccc}
\hline \multicolumn{1}{c}{ URAIAN } & SATUAN & BATASAN & & METODA UJI \\
\hline Komponen & $\%$ mol & MINIMAL & MAKSIMUM & \\
Metana & & 77 & & GPA 2261/ISO6974 \\
Etana & & 8 & GPA 2261/ISO6974 \\
Propana & & 4 & GPA 2261/ISO6974 \\
Butana & & 1 & GPA 2261/ISO6974 \\
Pentana & & 1 & GPA 2261/ISO6974 \\
Heksana & & 0,5 & GPA 2261/ISO6974 \\
Oksigen (O2) & & 3 & GPA 2261/ISO6974 \\
Nitrogen (N2) & & 0,1 & GPA 2261/ISO6974 \\
Karbondioksida (CO2) & & 5 & GPA 2261/ISO6974 \\
Hidrogen Sulfida (H2S) & ppm Volume & & 10 & ISO 2385/UOP 212 \\
Kandungan Uap air & & & 3 & ASTM D1142 \\
(H2O) & Lb/MMMSCFD & & &
\end{tabular}




\begin{tabular}{|c|c|c|c|c|}
\hline URAIAN & SATUAN & BATASA & & METODA UJI \\
\hline Merkuri $(\mathrm{Hg})$ & $\mu \mathrm{g} / \mathrm{m} 3$ & \multicolumn{2}{|c|}{ Dilaporkan } & ISO 6978 \\
\hline Ukuran Partikulat & $\mathrm{mg} / \mathrm{m} 3$ & \multicolumn{2}{|c|}{ Tidak ada } & ASTM7650 \\
\hline Densitas Relatif & & 0,560 & 0,850 & GPA 2172/ISO6976 \\
\hline Nilai Kalor & $\mathrm{BTU} / \mathrm{ft} 3$ & 960 & 1175 & GPA 2172/ISO6976 \\
\hline Indeks Wobbe & $\mathrm{BTU} / \mathrm{ft} 3$ & 1050 & 1313 & GPA 2172/ISO6976 \\
\hline Zat Pembau & & $\begin{array}{r}\mathrm{CNG} \\
\text { kadarny } \\
\text { ba } \\
\text { Flam }\end{array}$ & $\begin{array}{l}\text { rodor, } \\
\text { i bawah } \\
\text { ah } \\
\text { snya }\end{array}$ & ISO 13734/ASTM D6228 \\
\hline
\end{tabular}

Penggunaan drier memang dapat mengurangi kadar air, namun jika kadar air BBG dari kilangnya atau produsen BBG memang cukup tinggi, setelah melewati drienpun kadar uap airnya masih di atas spesifikasi SK Dirjen Migas. Dari kasus tersebut memang diperlukan spesifikasi gas yang cukup kering dari supplier gas (Pertagas dan PGN) sebelum masuk ke sistem pengisian BBG. Selain itu, gabungan antara zat inisiator korosi dan efek tekanan yang di sebabkan penggunaan bahan bakar dan pengisian yang berulang pada tabung dapat mengakibatkan keretakan pada material logam tabung penyimpanan sehingga memiliki potensi bahaya untuk keselamatan (safety). Cairan (kandungan Air) juga bisa menimbulkan suatu keadaan yang dinamakan "blockages" atau penyumbatan dalam sistem bahan bakar dari suatu kendaraan bermotor. Oleh karena itu, temperatur titik kondensasi (dew point water) BBG yang di keluarkan dari SPBG harus berada dibawah suhu lingkungan. Bila tidak ada kondensasi uap air, maka resiko korosi sangat minim sehingga baik ISO 11439 atau SAE J1616 tidak membatasi konsentrasi $\mathrm{CO}_{2}$.

Dalam ISO 15403-1 jelas mensyaratkan bahwa titik kondensasi dari BBG dalam tabung silinder harus rendah agar mencegah terjadinya kondensasi uap air dalam kondisi tekanan dan temperature tertentu sesuai dengan iklim dan geografisnya. Dalam standar ISO 15403-2 kadar air ditentukan berdasarkan temperature terendah yang pernah terdeteksi. Sedangkan menurut SAE J1616, jenis parameternya sama dengan parameter yang dibahas pada standar ISO 15403. Pada SAE J1616, temperatur Dew PointWater pada BBG disesuaikan dengan kondisi geografi pada kendaraan tersebut beroperasi sehingga proses kondensasi didalam tabung dapat dihindari pada tekanan operasi tabung.

Dalam standar SAE J 1616, disyaratkan bahwa untuk mencegah terjadinya kondensasi kandungan uap air dalam BBG, ditetapkan 5.6
${ }^{\circ} \mathrm{C}\left(10^{\circ} \mathrm{F}\right)$ dibawah temperatur terendah di negara tersebut. Data mengenai kondisi geografis dan temperature terendah yang terdeteksi dapat diperoleh dari negara yang tersebut. Tidak ada batasan untuk kandungan airnya, hanya direkomendasikan temperaturDew Point water harus dibawah 5.6 -C dibawah temperatur negara tersebut.

Jika mengikuti persyaratan ISO 15403-2 dan SAE J1616 dengan temperature terendah di Indonesia yang pernah terdeteksi sebesar $20^{\circ} \mathrm{C}$, maka batasan kadar airnya adalah 9,36 lb/MMScf, sementara batasan spesifikasi dalam SK Dirjen Migas 2011 adalah 3 lb/MMScf. Penurunan kadar air hingga 3 $\mathrm{lb} / \mathrm{MMScf}$ menyebabkan biaya operasional SPBG menjadi lebih besar karena semakin kecil kadar air di outlet dispenser, makin besar biaya operasional yang diperlukan (memasang dehidrator atau drier).

\section{KESIMPULAN}

Batasan mutu kadar air dalam bahan bakar gas (BBG) yang digunakan pada kendaraan bermotor di sektor transportasi darat sangat penting dijaga dan diperhatikan, khususnya di SPBG. Hasil pengukuran kadar air dalam bahan bakar gas di beberapa SPBG di beberapa wilayah di Indonesia teridentifikasi masih tinggi, di atas batasan spesifikasi yang ditetapkan yaitu $3 \mathrm{Lb} / \mathrm{mmscf}$. Tingginya kandungan air dalam bahan bakar gas di SPBG dikarenakan pada titik inlet gas masih mengandung kadar air yang tinggi. Pengendalian kadar air dalam bahan bakar gas (BBG) secara tepat dan kontinu akan mampu mengendalikan dan menjaga kualitas BBG yang digunakan pada sektor transportasi.

Gas feeding di Hulu maksimal 15 $\mathrm{lb} / \mathrm{mmscf}$ agar pengelola BBG dalam hal ini SPBG tidak terlalu berat dalam menurunkan kandungan air dalam BBG sehingga mampu memenuhi persyaratan spesifikasi BBG yang ditetapkan.Bahan bakar gas (BBG) sebagai 
bahan bakar alternatif untuk transportasi darat harus terus diupayakan dalam rangka menggalakkan enrgi bersih dan ramah lingkungan.

\section{UCAPAN TERIMAKASIH}

Dengan telah tersusunnya makalah ini, penulis sangat bersyukur pada Allah SWT yang telah memberikan banyak sekali kenikmatan hidup, salah satunya adalah nikmat sehat sehingga penulis dapat menjalankan tugas sehariharinya. Makalah ini dapat terselesaikan dengan adanya support dari temanteman,khususnya Divisi Teknologi Gas di PPPTMGB "LEMIGAS"

\section{DAFTAR PUSTAKA}

Rahardjo Tirtoatmodjo, Jurnal Teknik Mesin, Vol.1 No. 1.April 1999.

ISO 6976 Natural gas - calculation of calorific values, Density, Relative Density and Wobbe index from composition.

La Ode Muhammad Abdul Wahid, 2014 "Prospek BBG sebagai Bahan Bakar Gas Pengganti Bensin.Conference: Outlook Energi Indonesia, September 2014.

Lisna R, Yayun A, Nata P, 2014 "Laporan Kajian Rancangan Standar Nasional Indonesia (RSNI) Spesifikasi BBG untuk kendaraan Bermotor, PPPTMGB "LEMIGAS".

SAE J1616: 1994-02, Recommended Practice for Compressed Natural Gas Vehicle

ISO 15403: 2000, Natural gas- Designation of the quality of natural gas for use as a compressed fuel for vehicles.

NFPA 52: 2006, Compressed Natural Gas (BBG) Vehicular Fuel Systems Code.

Aziz ML, Paramita W, 2011. Potensi Pengembangan BBG Darat (terrestrial BBG) di Indonesia, Lembaran Publikasi Minyak dan Gas Bumi, Vol. 45, No.1: 17-23.
Tulus B. Sitorus, MT, 2002. Tinjauan Pengembangan Bahan Bakar Gas sebagai Bahan Bakar Alternatif, Jurusan Teknik Mesin, Fakultas Teknik Universitas Sumatera Utara.

Bukacek, R.F.,1955, "Equilibrium Moisture Content of Natural Gases", Research Bulletin 8. Institute of Gas Technology, Chicago, USA, 1955.

Robinson, J.N., Wiekert E., Moore R.G., Heidemann R.A., 1978. "Charts help estimate $\mathrm{H}_{2} \mathrm{O}$ content of sour gases". The Oil and Gas Journal (USA), February 6, 1978, pages 77-78.

ASTM designation D 1142-95, "Standard Test Method for Water Vapor Content of Gaseous Fuels by Measurement of Dew-Point Temperature". American Society for Testing and Materials, Philadelphia, USA, 1995.

Oellrich, L.R., Althaus, K, 2002. Relationship Between Water Content and Water Dew Point Keeping in Consideration the Gas Composition in the Field of Natural Gas. GERG Technical Monograph TM 14. Fortschritt-Berichte VDI, Nr 679, 2002.

ISO 9000:2008 Quality management systems - Fundamentals and vocabulary (Publikasi ISO)

Risdyanta,2008 Bahan Bakar Gas (BBG) sebagai alternative BBM untuk Transportasi, Forum Teknologi Volume. 05 No.2

LIPI, "Kebijakan Nasional Program Konversi BBM ke BBG untuk Kendaraan," Jakarta,2011.

R. E. Kirk and D. F. Othmer (eds.), Encyclopedia Of Chemical Technology. Vol. 7, Interscience Encyclopedia, Inc., New York, NY, 1951.

Sulfur Compound Emissions Of The Petroleum Production Industry, EPA650/2-75-030. U. S. Environmental Protection Agency, Cincinnati, $\mathrm{OH}$, 1974.

William D. McCain, 1990. The Properties of Petroleum Fluids, second edition, by Jr. Copyright Pennwell Books. 